\title{
PCT: Interventional Management of Cholecystitis
}

\author{
Ryan M Cobb ${ }^{1 *}$, Ian Sullivan D0 ${ }^{1 *}$, Brian W Berg ${ }^{2}$, Abhinav Patel ${ }^{2}$ and Gary S Cohen ${ }^{1}$ \\ ${ }^{1}$ Department of Diagnostic and Interventional Radiology, Temple University Hospital, USA \\ ${ }^{2}$ Lewis Katz School of Medicine at Temple University, USA
}

Submission: July 13, 2017; Published: August 23, 2017

*Corresponding author: Ryan Cobb, Temple University Hospital, Department of Diagnostic and Interventional Radiology, USA, Tel: 267-309-1229; Fax: 215-707-2428; Email: ryan.cobb@tuhs.temple.edu

Ian Sullivan, Temple University Hospital, Department of Diagnostic and Interventional Radiology, USA, Tel: 603-913-4090; Fax: 215-707-2428;

Email: ian.sullivan@tuhs.temple.edu

\begin{abstract}
Percutaneous cholecystostomy tube (PCT) placement has traditionally served as a temporizing measure to bridge a comorbid patient presenting with acute cholecystitis and/or acute cholangitis to the current mainstay definitive treatment of cholecystectomy. While criteria outlined by the 2013 revision of the 2007 Tokyo Guidelines have subsequently resulted in a rise of PCT placements, but a definitive treatment plan is lacking in cases where surgery is forgone due to excessive perioperative risk. In our single institutional retrospective analysis of acute cholecystitis patients, a majority underwent PCT, not cholecystectomy for definitive management. Within this subset of patients a majority was lost to follow up and some patients required permanent tube placement. Our findings demonstrate a deficiency in the treatment plan for cholecystitis, one that we feel interventionalists are uniquely suited to fill.
\end{abstract}

Keywords: Percutaneous cholecystostomy; Cholecystitis; Tokyo Guidelines; Interventional radiology; Minimally invasive

Abbreviations: PCT: Percutaneous Cholecystostomy Tube

Text

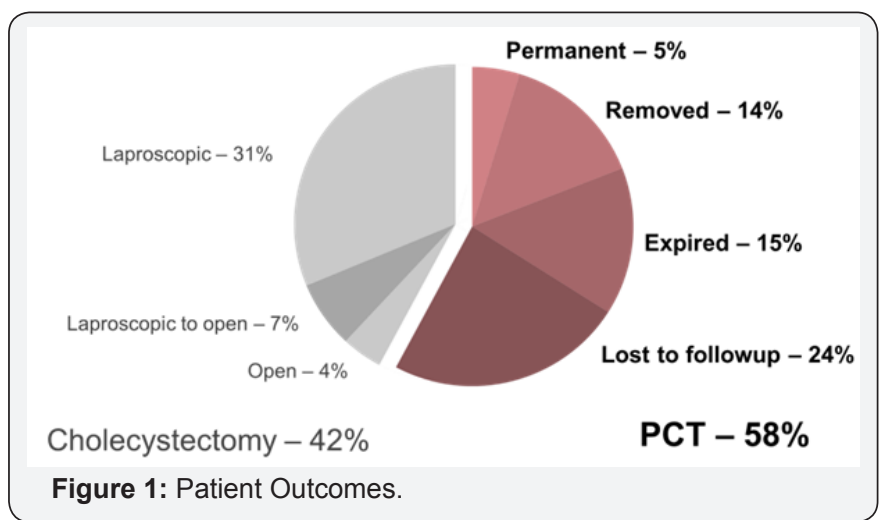

Percutaneous cholecystostomy tube (PCT) placement has traditionally served as a temporizing measure to bridge patients presenting with acute cholecystitis to the mainstay of cholecystectomy. The most recent and relied upon treatment decision algorithm is the 2013 revision of the 2007 Tokyo guidelines. According to these guidelines, a patient presenting with moderate or severe acute cholecystitis may be referred to interventional radiology for PCT either as a bridge to cholecystectomy or to the less definitive outcome of observation (Figure 1) [1,2]. The course of treatment for patients under observation is variable: Patients may undergo PCT removal or subsequent cholecystectomy and some may require permanent PCT due to comorbidities precluding surgery. Others may simply be lost to follow-up after they leave the hospital.

At our institution, we decided to reshape the role of interventionist in the interdisciplinary care team managing acute cholecystitis patients. In order to assess opportunities to optimize patient outcome, we performed a retrospective analysis of patients that underwent PCT between February 2011 and February 2016. We found 147 patients (67 females and 80 males) with a mean age of 64.4 years (range 22-91yo, SD 16.0

years) received a PCT during this period. Patient endpoints analyzed included cholecystectomy (laparoscopic, conversion to open, or open), PCT removal, mortality and loss to follow-up.

Outcomes of the 147 patients are as follows (Figure 2): 62 $(42.2 \%)$ received a cholecystectomy. In the cholecystectomy group, 46(74.2\%) were laparoscopic, 10 (16.1\%) laparoscopic with conversion to open, and 6 (9.7\%) underwent open cholecystectomy. 22 of the total $147(15.0 \%)$ expired with the tube in place. 21 of 147 (14.3\%) had the tube removed as 
definitive treatment. 7 of 147 (4.8\%) were under observation with indefinite tube management at the time of data collection.

35 of 147 (23.8\%) were lost to follow-up at the time of data collection.

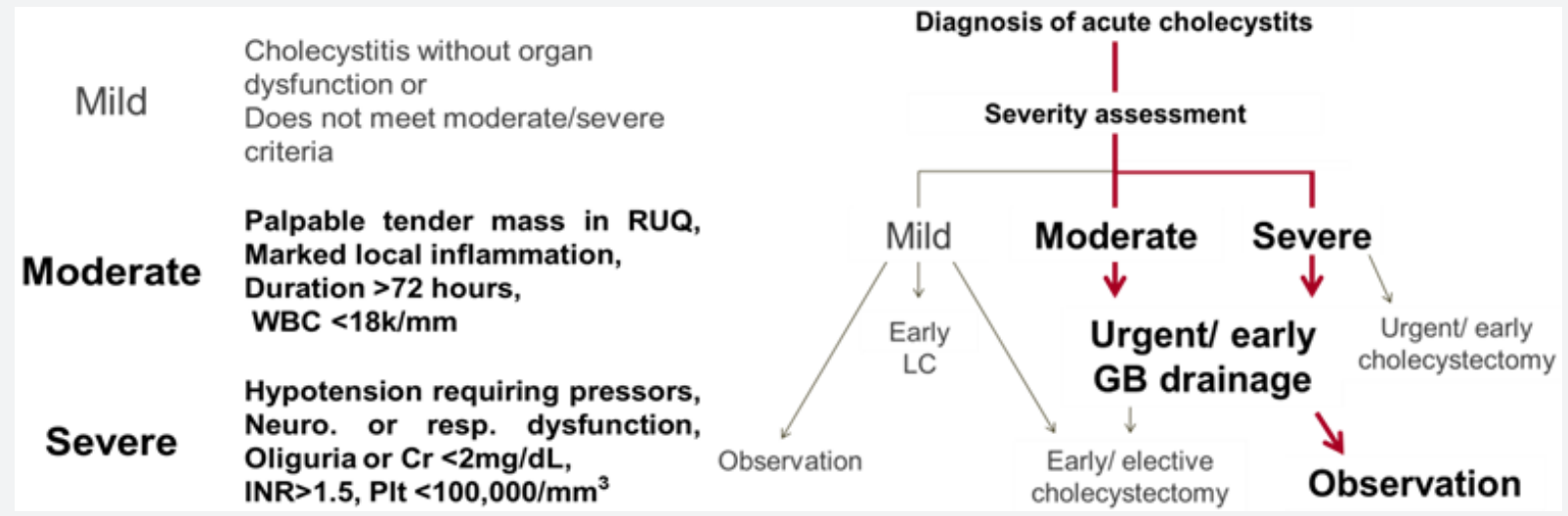

Figure 2: Cholecystitis Severity and Tokyo Guidelines Treatment Algorithm [1].

Standard of care relegates management of patients status post PCT placement to general surgery with minimal interventional team involvement. While a portion of these patients will be bridged to surgery, some remain too high risk to undergo cholecystectomy. In our hospital, the rate of conversion to open cholecystectomy for patients with chronic and acute cholecystitis exceeds reported averages of $6.1-10 \%$ [3]. While this statistic can be attributed in part to the multiple and severe comorbidities exhibited by our hospital's demographic, composed mainly of the underserved, transplant recipients and cancer patients, we believe our high conversion rate also demonstrates a need for closer clinical management and alternative definitive treatment options.

Interventionalists are uniquely positioned to take on primary management role within this complicated population. Definitive options for management by PCT including criteria for catheter removal, utilization of fluoroscopic or endoscopic stone removal and the novel therapy of gallbladder sclerosis are concept proven [4-6]. However, the integration of interventionalists as part of an interdisciplinary treatment algorithm requires further development. TUH Interventional Radiology is currently in the process of establishing a primary percutaneous cholecystostomy clinic to manage patients from tube insertion to completion of treatment, regardless of end treatment. Through this system, we hope to develop a unique clinical decision tree to assist in management of PCT patients at our institution.

\section{References}

1. Yokoe M, Takada T, Strasberg SM, Solomkin JS, Mayumi T, et al. (2013) TG13 diagnostic criteria and severity grading of acute cholecystitis (with videos). J Hepatobiliary Pancreat Sci 20(1): 35-46.

2. Miura F, Takada T, Kawarada Y, Nimura Y, Wada K, et al. (2007) Flowcharts for the diagnosis and treatment of acute cholangitis and cholecystitis: Tokyo Guidelines. J Hepatobiliary Pancreat Surg 14(1): 27-34.

3. Livingston E, Rege R (2004) A nationwide study of conversion from laparoscopic to open cholecystectomy. Am J Surg 188: 205-211.

4. Wong SK, Yu SC, Chung SS (1994) Percutaneous cholecystostomy and endoscopic cholecystolithotripsy in the management of acute cholecystitis. Surg Endos 13(1): 48.

5. Kim HY, Kim YJ, Shin TB (2011) Fluoroscopy-Guided Percutaneous Gallstone Removal Using a 12-Fr Sheath in High-Risk Surgical Patients with Acute Cholecystitis. Korean J Radiol 12(2): 210-215.

6. Lee TH, Park SH, Kim SP, Park JY, Lee CK, et al. (2009) Chemical ablation of the gallbladder using alcohol in cholecystitis after palliative biliary stenting. World J Gastroentrol 15(16): 2041-2043.

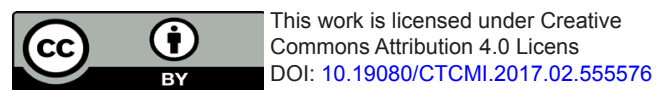

\begin{tabular}{|l|}
\hline \multicolumn{1}{|c|}{ Your next submission with Juniper Publishers } \\
will reach you the below assets \\
- Quality Editorial service \\
- Swift Peer Review \\
- Reprints availability \\
- E-prints Service \\
- Manuscript Podcast for convenient understanding \\
- Global attainment for your research \\
- Manuscript accessibility in different formats \\
( Pdf, E-pub, Full Text, Audio) \\
- Unceasing customer service \\
Track the below URL for one-step submission \\
https://juniperpublishers.com/online-submission.php \\
\hline
\end{tabular}

